\title{
FOTOGRAFIA E PRÁTICA DE SI: ENTRELACES ENTRE ARTE, AFETOS E COTIDIANO
}

\author{
PHOTOGRAPHY AND SELF PRACTICE: \\ INTERLACES BETWEEN ART, AFFECTED AND EVERYDAY
}

Fernanda Ayumi Sakuma ${ }^{1}$

Roberta Stubs ${ }^{2}$

\begin{abstract}
Resumo: Este artigo tem como proposta pensar um processo de criação artística que se utiliza da fotografia para a potencialização de transbordamentos, sentimentos, vivências e acontecimentos. Considerando esta proposta, surgiu a problemática: como a fotografia cotidiana pode possibilitar singularizações, práticas de si e a criação de outras realidades a partir dos acontecimentos que permeiam meu dia a dia? Para responder à essa problemática, me respaldo em autores como Suely Rolnik e Félix Guattari (2013) no livro "Micropolítica: cartografias do desejo" e Suely Rolnik (1997), com eles, busco relações entre processo artístico e subjetividade.
\end{abstract}

Palavras-chave: Fotografia; singularização; afetos; artes.

\begin{abstract}
This article proposes to think about an artistic creation process that uses photography to enhance overflows, feelings, experiences and events. Considering this proposal, the problem arose: how can everyday photography enable singularities, self-practices and the creation of other realities from the events that permeate my daily life? To answer this problem, I rely on authors such as Suely Rolnik and Félix Guattari (2013) with the book "Micropolitics: cartographies of desire" and Suely Rolnik (1997), with them, I look for relationships between artistic process and subjectivity.
\end{abstract}

Keywords: Photography; singularities; affections; art.

\section{Os primeiros passos...}

De início, não queria realizar uma pesquisa em artes, pois sabia que iria escavar afetos e teria que me aprofundar nos mesmos, mas, conforme a pesquisa foi avançando, percebi que mergulhar nesse processo foi importante tanto para a vida acadêmica, quanto para minha vida pessoal, funcionou como uma espécie de manifesto de libertação no qual que exerço uma prática de liberdade.

Segundo Sandra Rey (1996), nas Artes Visuais, a pesquisa pode ser caracterizada em duas vias, pesquisa $\mathrm{em}$ artes e sobre artes. A pesquisa sobre arte referência as pesquisas envolvendo o produto final, ou seja, a arte já pronta, em circulação. Já a pesquisa em artes tem como especificidade o estudo dos processos, das bases de produção e da fundamentação teórica. Para a autora, uma obra é ao mesmo tempo um processo de formação de algo e um processo de formação de sentidos, pois a obra:

[...] perturba o conhecimento de mundo que me era familiar antes dela: ela me processa. Também nesse sentido, de fazer um processo a alguém: sim, somos processados pela obra. A obra, em processo de instauração, me faz repensar os meus parâmetros, me faz repensar minhas posições. O artista, às voltas com o processo de instauração da obra, acaba por processar-se a si mesmo, colocando-se em processo de descoberta. Descobre coisas que não sabia antes e que só pode ter acesso através da obra.

\footnotetext{
${ }^{1}$ Universidade Estadual de Maringá - UEM.

${ }^{2}$ Universidade Estadual de Maringá - UEM.
} 
Neste trabalho, tenho a fotografia como substrato de produção de sentidos, e conforme me aprofundava na construção e na pesquisa sobre fotografias, pensava também sobre minha posição em relação ao território à qual me encontro, seja no afetivo ou no acadêmico, possibilitando um trabalho de autoconhecimento. Então, a qual território estou me referindo? Uma palavra que aparece muito em meu trabalho é silêncio, e ela também é uma característica bem presente nas famílias japonesas, que tem uma cultura de silêncio, de não se manifestar contra, de não responder, de aceitar circunstâncias sem perguntar o porquê.

Assim, neste território, busco com e a partir da fotografia, registrar afetos, dualidades e acontecimentos. Busco perguntar "Por que?", construindo uma série que mexe com o sensível e que estranhe as certezas, que pode tanto cair para se reconstruir quanto crescer e crescer... até ter de escolher outras direções.

\section{Entrelaces entre fotografia, subjetividade e cotidiano}

Os conceitos de subjetividade, dobra e singularização aparecem de forma a potencializar a escrita e a compreensão de um campo conceitual que vê na vida uma potência de variação, de diferença, de recusa e de resistência. Assim, a partir de autores como Félix Guattari e Suely Rolnik (2013) e Suely Rolnik (1997), estarei abordando esses conceitos, que servem de alicerce para a construção desta pesquisa junto ao processo artístico que a permeia.

Segundo Guattari e Rolnik (2013), a subjetividade não possui uma natureza humana e sim maquínica, sendo ela essencialmente fabricada, modelada, recebida e consumida. Essa subjetividade não implica posse, mas sim uma produção contínua que acontece a partir de encontros que vivemos com o outro, e este outro pode ser entendido como tudo aquilo que produz efeitos nos corpos e nas maneiras de viver. Ou seja, tudo o que marca "[...] no próprio coração dos indivíduos, em sua maneira de perceber o mundo, de ser articular com o tecido urbano, com os processos maquínicos do trabalho e com a ordem social suporte dessas forças produtivas." (GUATTARI, ROLNIK, 2013, p. 34)

Mas então, como posso ter a fotografia como meio para trabalhar subjetividades e afetos? Como dito anteriormente, a subjetividade é formada por diversos componentes que são resultantes desses encontros com o outro, de uma apreensão parcial que o indivíduo realiza de elementos presentes no contexto social de cada um, e assim, nesse sentido:

[...] valores, ideias e sentidos ganham um registro singular, tornando-se matéria prima para expressão dos afetos vividos nesses encontros. Essa produção de subjetividade, da qual o sujeito é um efeito provisório, mantémse em aberto uma vez que cada um, ao mesmo tempo em que acolhe os componentes de subjetivação em circulação, também os emite, fazendo dessas trocar uma construção coletiva viva. (MANSANO, 2009, p. 111)

Ao ganharem essa importância coletiva, essa subjetividade pode ser modificada, reinventada de acordo com o cotidiano de cada indivíduo de forma a gerar linhas de fuga, novas texturas, escapes de uma subjetividade vigente. Falamos, pois, de processos de singularização, tal como denominado por Guattari e Rolnik (2013). Mas, assim como a subjetividade pode gerar linhas de fuga e se reinventar, ela também pode ser reproduzida de uma maneira a não se afetar por essas linhas, esvaziando-se e perdendo sua potência criativa. Nesse sentido, o que caracteriza um processo de singularização é que ele seja automodelador que, ao captar os componentes de uma subjetividade, ele construa sua própria referência sem necessitar reproduzir outras já "feitas". Quando começamos a adquirir a liberdade de construir nossas referências, passamos a ter a capacidade de ler a situação e tudo o que a contorna com mais 
frescor e atenção às linhas de diferenciação. Assim, neste trabalho, eu parto da realidade como elemento já dado, já feito, mas a partir do momento em que eu a fotografo, tenho a liberdade de construir minhas próprias referências, minhas próprias narrativas.

Segundo Kossoy (2012) em seu livro 'Fotografia \& História', a fotografia possui duas principais características, o tempo interrompido e a segunda realidade. Para o autor, a segunda realidade seria o que ficou na bidimensão, capturada, interrompida e isolada, mas que nos possibilita pensar as múltiplas realidades a partir de nossos encontros com essas fotografias. São nesses encontros com a imagem fotográfica que múltiplos campos de sensações e sentidos podem se abrir, sendo um canal de potencialização de afetos e também ressignificação de imagens.

Dessa maneira, a fotografia, junto ao gesto de interrupção, nos capacita a criar poéticas e estéticas fora de padrões predeterminados. Agindo como uma operação delatora, uma arte parteira que ilumina as coisas que já estavam presentes, mas não eram vistas. Acontecimentos como uma florzinha que começou a nascer no concreto; os clips no meio da rua; os elásticos de cabelo que encontramos pelo caminho; a senhora que faz o mesmo caminho todo dia para comprar pão no mesmo horário e na mesma padaria; um cachorro que está sempre em frente a um estabelecimento; o tédio de uma dona de casa que vê graça em mudar os móveis de lugar a cada duas semanas; os cachorros tirando um cochilo de tarde enquanto desenvolvo essa pesquisa poética.

Os principais acontecimentos delatores em meu cotidiano ocorrem em meio a parentes, com os quais tenho bastante contato. Passei várias manhãs e tardes na companhia de minha avó e tias, e fui percebendo que, mesmo silencioso, o território também era turbulento. Passei a ver de maneira diferenciada, a perceber momentos, conversas e até mesmo interferir em alguns casos com alguns questionamentos inesperados, como se estivesse fazendo um estudo daquele território, com um olhar de estrangeira dentro de minha família.

\section{Território afetivo, o que é este território?}

Para melhor falar sobre este território afetivo, que é onde estabeleço um certo campo da pesquisa, penso ser interessante falar um pouco sobre a toxicomania de identidade e dinâmica das dobras que constituem nossa subjetividade. Suely Rolnik (1997), em seu texto 'Uma insólita viagem à subjetividade: fronteiras com a ética e a cultura', nos direciona em meio às relações entre sujeito e subjetividade e suas fronteiras com a cultura e a ética. A autora explica o 'funcionamento' da subjetividade a partir de etapas. A primeira etapa consiste naquela visão que temos de uma subjetividade imutável, como um modo de ser, agir e pensar, e que vê o interior e o exterior como independentes e separados um do outro. Na segunda etapa, somos tocados por uma potencialidade vibrátil, e, então, captamos uma certa inquietação na pele, que seria o exterior, como se algo estivesse fora do lugar.

Ao percebermos essa inquietação, passamos para a terceira etapa, na qual estendemos essa pele inquieta formando uma superfície plana, mas que não se mantém plana devido aos incômodos. Essa pele então começa a se dobrar e formar curvaturas, possibilitando entradas e enfim formando uma subjetividade diferente da do início, tida até o momento como uma forma de ser e agir imutável. Com o tempo, outros fluxos e acontecimentos adentram esta pele formando outras configurações. Onde havia uma dobra, ela se desfaz e a pele volta a se estender, ao mesmo tempo em que se curva em outro local, ficando claro que cada modo de existência pode ser pensado como um conjunto de dobras singulares de subjetivação.

$\mathrm{Na}$ quarta e última etapa, o dentro e o fora, o interno e o externo que víamos como algo dissociável, agora nos é indissociável e, paradoxalmente, inconciliáveis. Numa dança contínua de dobrar-se e desdobrar-se, vemos que o dentro detém o fora e o fora desmancha o dentro, tal como sinaliza Rolnik (1997, p. 2): 
[...] o dentro é uma desintensificação do movimento das forças do fora, cristalizadas temporariamente num determinado diagrama que ganha corpo numa figura com seu microcosmo; o fora é uma permanente agitação de forças que acaba desfazendo a dobra e seu dentro, diluindo a figura atual da subjetividade até que outra se perfile.

Mas o que seriam essas forças que nos atravessam e transversalizam? Mansano (2009), faz menção à força de recordar, conceber, imaginar e querer que formam nossa subjetividade na medida que experienciamos essas forças do mundo em nosso cotidiano e nas nossas vivencias. Tais forças geram marcas que dizem tanto da suposta interioridade do sujeito quanto daquilo que diz do mundo. São dobras de subjetivação no qual dentro e fora se confundem e se transmutam.

Conforme novas configurações adentram essa pele que chamamos aqui de subjetividade, tais dobras seguem continuamente se formando, se tornando planas e se curvando em outros locais. É por conta dessa vibratibilidade da pele que conseguimos entender o sujeito e sua subjetividade como algo que não pode ser concebido como uma entidade já pronta, mas sim que se constitui à medida em que entra em contato com forças que o perturbam e o afetam de diferentes maneiras.

Ainda em relação ao texto de Rolnik (1997), a autora comenta que em certos modos de subjetivação a formação de dissolução das dobras tendem a fluir melhor do em que em outras. A autora traz a subjetividade do artista como exemplo, em que os produtores culturais de qualquer meio tendem a ser especialmente capazes de suportar as vertigens da desestabilização provocada pelas forças que inquietam a pele. Isto porque, é inicialmente em microuniversos culturais e artísticos que relações de forças ganham força, corpo, sentido e valor, e nesses microuniversos artísticos vivem cartografias musicais, visuais, cinematográficas, teatrais, arquitetônicas, literárias, filosóficas, etc.

Ao deixar isso claro, Rolnik (1997, p. 4), também afirma que:

[...] quando uma dobra se faz e, junto com ela, a criação de um mundo, não é apenas um perfil subjetivo que se delineia, mas também e indissociavelmente, um perfil cultural. Não há subjetividade sem uma cartografia cultural que lhe sirva de guia; e, reciprocamente, não há cultura sem um certo modo de subjetivação que funcione segundo seu perfil.

Claramente, não existem apenas subjetividades artísticas, na realidade o processo de formação e dissolução de figuras de subjetividade tende a ser interrompido de várias maneiras. A autora traz o termo "toxicomania de identidade" para definir essa interrupção, representando um viciado em identidade que, tendo horror às forças que adentram sua pele e a desestabilizam, ele procura se manter em apenas uma dobra, deixando entrar apenas as forças que não ponham em risco sua identidade. Esse indivíduo é aquele que vê o dentro e o fora simplesmente como uma visão espacial, que acredita que o dentro é imutável e já dado em total equilíbrio. Consequentemente, não permite a produção do novo, pois se algo já está dado e em equilíbrio, não tem possibilidade de mudança. Podemos ver a toxicomania de identidade como aquela relação com a subjetividade em que se tem alienação e opressão, onde o indivíduo se submete à subjetividade, às linhas do tempo, às forças tal como as recebe, consequentemente não entra em um processo singularizador.

Após ler e compreender a toxicomania de identidade e as maneiras com as quais um sujeito lida com a subjetividade, percebi o quanto o vício em identidade está presente no meio familiar no qual me situo. Falo do meio familiar, pois ele servirá de substrato de produção poética em meu trabalho, um trabalho que tem como principal eixo a evocação de afetos através de silenciamentos, lacunas e vazios. Esses silêncios muitas vezes geram fraturas afetivas, e ao enxergar o silêncio como uma subjetividade alienada, uma característica de um vício de identidade, procuro, através da 
fotografia e desse próprio silêncio, costurar essas fraturas permitindo que elas se revelem e se curem ao mesmo tempo. Além do silêncio, os assujeitamentos aos quais algumas mulheres são colocadas devido a linhas de subjetivação ligada à tradição: o fato de não poderem viajar sozinhas, não tomarem decisões em casa, não poderem trabalhar para não desagradar o marido, não terem um poder de intervenção e ficarem em um local de impotência.

Em relação a essa sujeição, li em uma tese de Mina Isotani (2016), que fala sobre a mulher japonesa moderna, sobre o termo Ryôsai Kenbo, que significa "Boa mãe, mãe sábia", termo que foi popularizado pelo ministério da educação do Japão, que traduzia o comportamento esperado das mulheres. Segundo Isotani (2016, p. 44):

O termo expressa o controle do Estado sobre a construção da mulher como objeto nacional, sendo uma ferramenta da engrenagem para a conquista da supremacia japonesa sobre outras nações. Isto é, a propaganda afirmava que ser uma boa esposa e uma mãe sábia era função primordial da mulher como parte contribuinte do país. Contudo, a mensagem escondia o fato de que as mulheres não podiam participar de decisões políticas ou ocupar cargos de destaque nas empresas.

Ainda hoje, o Japão traz desdobramentos desse controle que ficou enraizado na subjetividade japonesa, e que se arrastam até os descendentes fora do país. Fui atrás dessas informações porque as mulheres de minha família me chamaram atenção e também pelo fato de ser mulher. Fui ouvindo algumas histórias como: abandono de estudo porque não podia ficar sozinha enquanto os pais e os irmãos iam viajar; sobre não poder seguir uma carreira que gostava por não ser visto como uma profissão de uma mulher direita; e o que ouvi mais recentemente - "Você tem que arrumar a casa quando eles chegarem, senão o que pensarão de nós?”.

Os elogios que são proferidos de algumas bocas, como: "Viu como é educada? Lavou a louça depois do café" ou "Comportada ela, quieta, não é escandalosa". Como se a educação se reduzisse somente a isso, em alguns valores que foram enraizados e que buscam se manter como norma. $\mathrm{O}$ fato de não se ter um questionamento sobre vários porquês, como: por que devo ser quieta? Porque não posso fazer um escândalo? - mesmo algumas situações me peçam por isso - Por que quando lavo louça sou considerada educada? E conforme fui escrevendo, pesquisando e tentando viver essa pesquisa, compreendi que se tratava justamente de um vício de identidade, de uma toxicomania de identidade. Isto é, busca se manter somente em uma dobra, em uma maneira de pensar, estagnada que não se move conforme o tempo passa, ou que simplesmente não considera o próximo como um sujeito que vibra em outras intensidades.

Sobre como o sujeito lida com a subjetividade vigente que nos é empurrada, Michel Foucault (2004) nos fala sobre a estética da existência, que, assim como o processo de singularização, busca criar um estilo próprio de nos tornarmos autores de nosso próprio território de criação, de existência. É uma maneira de pensar os processos de singularização menos ligado às linhas de poder e assujeitamento, mas sem esquecer que essas linhas de poder, assujeitamento, alienação continuam ali nos atravessando de várias maneiras...

A estética da existência surge de uma urgência que não deseja mais obedecer aos códigos que constrangem e regulam a vida em seus mínimos aspectos. Deseja um pensamento não dogmático que não impõe mais certezas absolutas ou constantes, jogando com as possíveis liberdades em um campo minado, para dar outra forma, sentido e valor as atitudes e comportamentos de nossa vida. É um princípio que regula práticas, técnicas e artes que visam modos de subjetivação não mais assujeitadas e assujeitadoras, caracterizadas como uma prática de si ou de liberdade. 


\section{Prática de si, fotografar-se}

Ao possibilitar um retorno a nossa vida e de um cuidado de si, que consequentemente diz respeito às nossas relações, penso que as fotografias aqui apresentadas podem ser vistas como pequenos exercícios de práticas de liberdade. Desde o momento em que há o recorte das fotografias, ao mesmo tempo em que há a construção de outras realidades que reverberam da foto, existe ali uma vontade de liberdade, de gerar e costurar fraturas revelando tanto o corte quanto a costura, como se estivesse dentro e fora ao mesmo tempo...

A liberdade em si é a questão mais difícil e delicada, ela depende da criação, da invenção, intensidade, experimentação constantes e permanentes, ela não pode se estagnar. Segundo Figueiredo (2010, p. 298), “A arte de viver ou a estética da existência é um bom princípio para se organizar estratégias, técnicas ou práticas para colocar a própria vida, a possibilidade de diferentes ou outros possíveis modos de vida."

As fotografias presentes nesse trabalho podem ser vistas como um pequeno exercício de práticas de liberdade, e, consequentemente, como uma maneira de não me anestesiar frente aos acontecimentos que me rodeiam, intensificando-os ao fragmentar a realidade deixando de fora a continuação do mundo. Como uma maneira de viver aquele momento cada vez mais de maneiras diferentes. Ao ver a vida como um emaranhado de acontecimentos, um rizoma que não possui nem início, nem fim, e sim várias pontas pelas quais podemos realizar outras múltiplas conexões, caminhando sem considerar a linearidade dos fatos e sim nos entregando ao acaso, vamos compondo diversos "e..." que nos arrasta para diversas outras direções... É uma vida que possibilita respiros, que não vê problema em parar e seguir outros rumos, até porque o que se conquistou seguindo certo caminho permanece conosco mesmo que peguemos outros rumos. Pegamos pedaços pela metade e juntamos com outros, formando novas configurações rizomáticas... Segundo Garlet (2014, p. 47):

[...] se perguntarmos ao rizoma se é este o melhor caminho a seguir, ele nos dirá: não tenho a menor idéia... Tem este... e Mais aquele... E mais aquele outro... E ainda aqueles vários outros que são possíveis, mas não tenho como lhe garantir se são os melhores, sei apenas que podes te tornar diferente do que és, nem melhor, nem pior, apenas diferente.

Ao tomar esses diferentes rumos e nos percebermos diferentes de antes, nos damos conta de que somos aquele sujeito que não é preconcebido, somos formados por direções, forças e fluxos que nos atravessam e, a cada atravessamento, nossas texturas e maneiras de ver o mundo se abalam formando novas. 

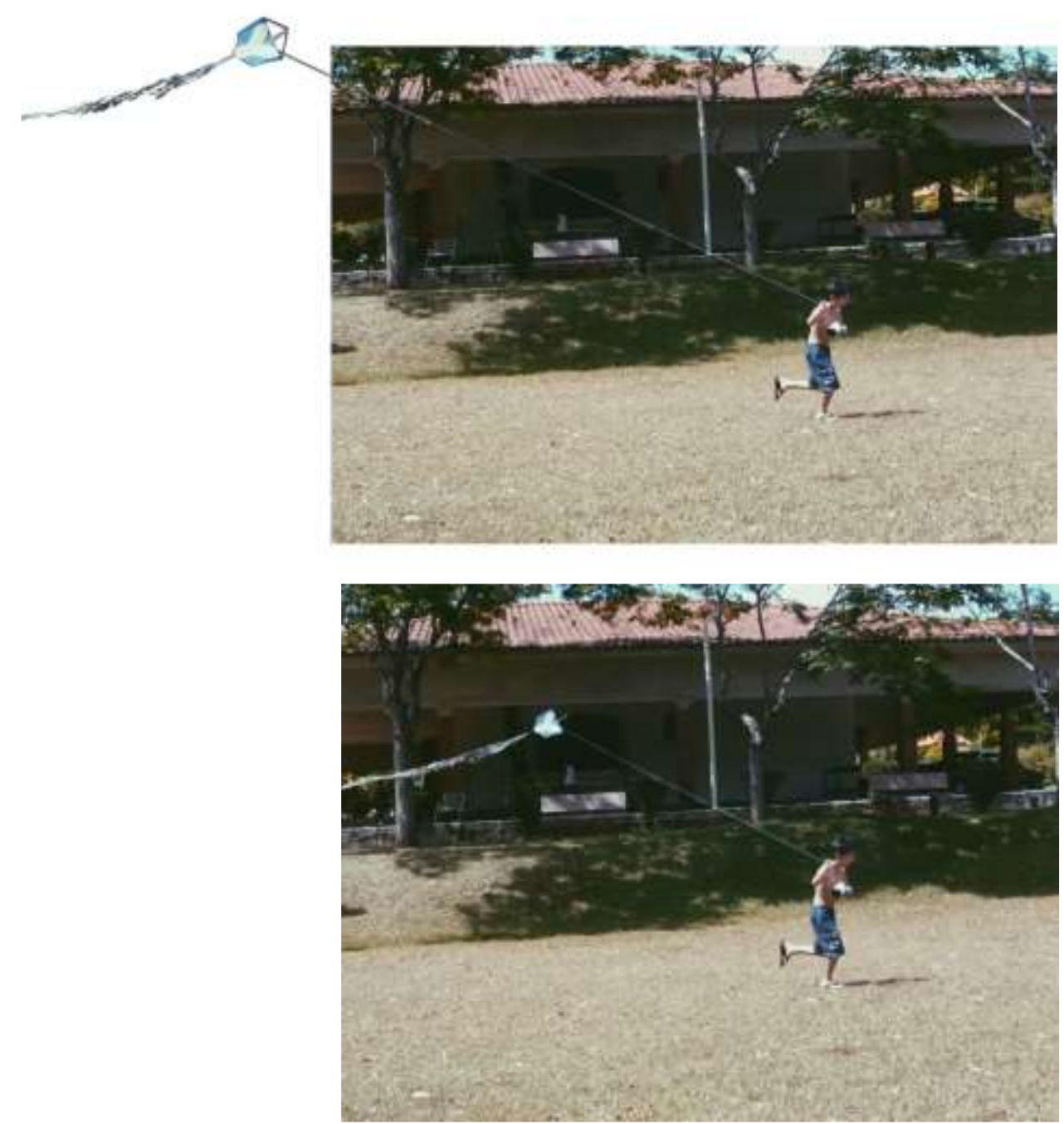

Imagem 1 - Menino pipa - Fonte: Registro pessoal, 2007

Ele já não está pequenino como na foto, já não gosta mais de empinar pipas, a construção provavelmente está terminada, o carro que se encontra no fundo foi vendido, está rondando em algum lugar da cidade ou em um ferro-velho, mas foi um local de muitas memórias... do momento, lembro-me bem pouco, sei que eu a congelei, mas o que aconteceu, não tenho nenhuma lembrança ou postulados seguros, mas independente de quem a olhar, vários sentidos e direções sairão dela, desencadeando vários porvires na imagem.

Ao ver essa foto tive um desejo de interferir nela, como aquela que interfere no acontecimento que teve no passado, mas com uma singularidade formada no agora e que estará em constante formação sem um fim definido. Ao mesmo tempo em que interfiro como uma forma de apresentar uma nova singularização, apresento também um escape da realidade, como diz Luersen (2018), um acontecimento que participa de duas temporalidades, que pertence tanto ao cronos, que é a linha cronológica em si que segue uma certa linearidade, como ao aion, que é o tempo flutuante, indefinido e que funciona como uma fuga incessante do presente e não cessa de dividir-se.

Ao trabalhar com o cotidiano como substrato de produção, o que esperava era encontrar diferenças que me fariam olhar mais atentamente, mas, na verdade, não são bem diferenças, e sim elementos que não se mostravam antes e que com a fotografia consigo revelar, e consequentemente, me revelar também. Afinal, é "na tessitura do cotidiano, daquilo que nos está mais próximo e que nos é mais familiar que podemos evocar uma ética-estética-política de 
invenção de si." (STUBS, 2015, p. 155). Tessituras essas, bordadas por acontecimentos esperados e inesperados, por conversas na faculdade, no trânsito, e com mais abundância no meio familiar. Este meio, o qual aparecerá com mais frequência em meu trabalho, é um meio, um território em que as singularidades são reprimidas... repressão que tem como consequência um rompimento de tempos em tempos e cria fraturas no que é dado como normal, como ordinário, nesse dia-a-dia no qual tento narrar meus olhares e sensações.

Os parentes com quem convivo desde pequena, os avós que visito todo final de semana, as conversas que escuto, os comportamentos em uma sala de estar, as tradições nos dias festivos, as prateleiras cheias de fotografias que ficam escondidas embaixo da escada, os afetos (muitas vezes reprimidos) que aparecem em alguns momentos... "São acontecimentos que muitas vezes nos provocam de forma inesperada, nos afectam e nos convidam a construir novos sentidos para práticas vividas." (MARTINS, VAZ, 2016, p. 439).

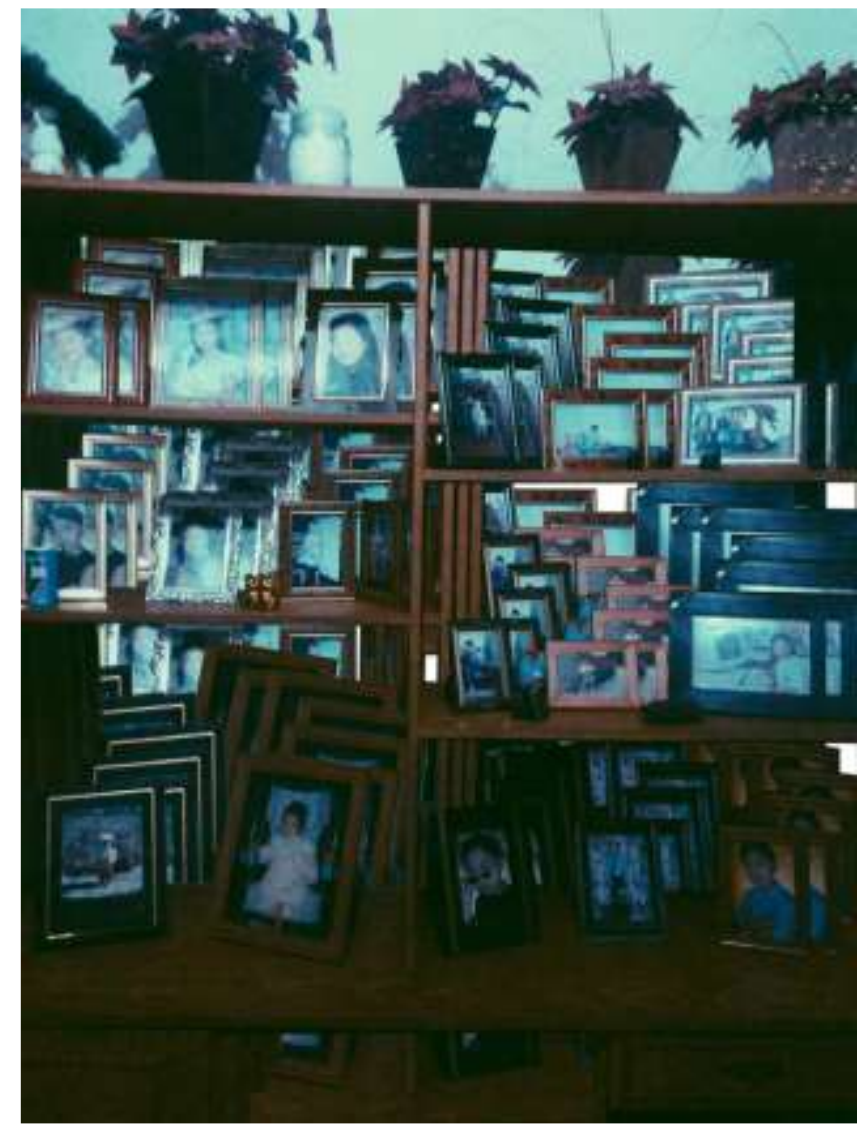

Imagem 2 - Afetos intensos e escondidos - Fonte: Registro pessoal, 2018

A foto acima foi manipulada digitalmente a partir de uma fotografia que fiz de uma prateleira que está na casa de minha avó há muito tempo. Esta prateleira existe desde que eu era pequena, as fotos estão no lugar onde sempre estiveram, somente algumas flores foram colocadas no topo, mas ela sempre esteve embaixo da escada. De início não reparava muito, mas é o que se vê de primeira mão logo que se sai do banheiro da casa, e comecei a pensar o porquê não mudavam esta prateleira de lugar... não tive respostas certeiras para a questão, mas a tomei como um material intenso de demonstração de afeto dentro da cultura oriental, que é caracterizada pela repressão dos afetos. Quando digo repressão, quero dizer que os afetos estão contidos, não quer dizer que eles não existem. Dessa maneira, a multiplicação das fotografias, que apresentam momentos de nascimento, de formatura na escola, de um passeio no parque entre muitos outros, reverberam em nós as dobras formadas pela ausência e presença de afetos. 
Um contraste com a imagem que está saturada de outras fotografias ao mesmo tempo que estão reprimidas ali, não podendo sair daquela estante escondida.

A demonstração de afeto para a tradição japonesa é algo que não deve ser mostrado em público, mas isso é desde um abraço a um beijo. Não se deve responder os mais velhos, por mais que ele esteja errado. Fui criada em um meio no qual alguém dizia algo, eu não me sentia no direito de perguntar 'por que? Um meio que pensa demais no que os outros vão pensar de ti, que muitas vezes valoriza o que não precisava ser tão valorizado e deixa passar o que tinha de mais cintilante em sua vida. Tive um olhar mais atento as mulheres da casa, que desde cedo convivo e ouço histórias as quais conseguia perceber que deixaram para trás coisas que consideravam importantes somente pelo fato de que deviam respeitar as vontades alheias.
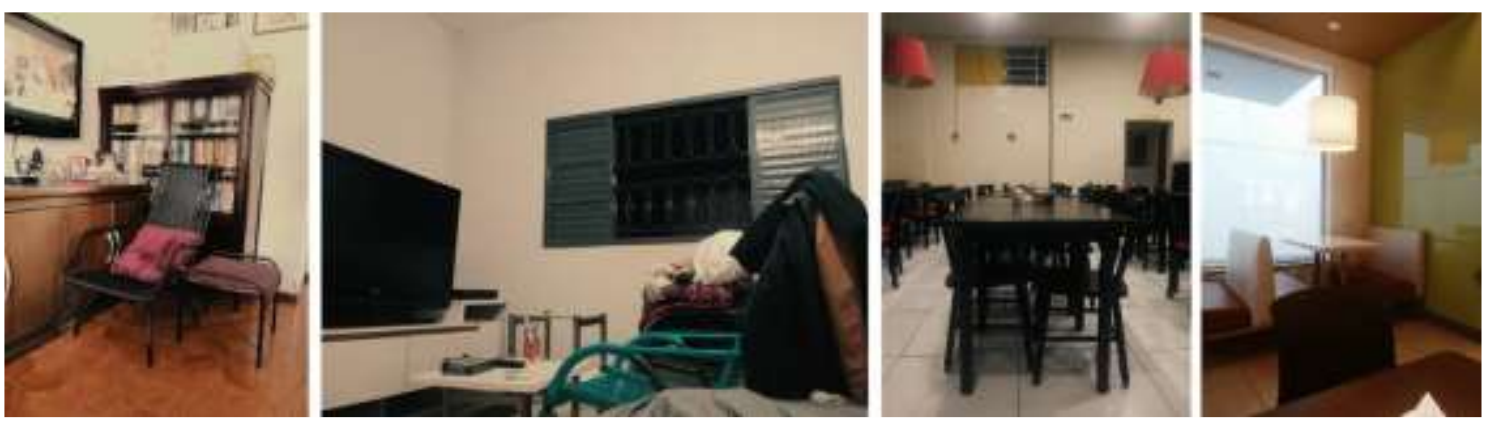

Imagem 3 - Vazios evocatórios - Fonte: Registro pessoal, 2018-2019

Cadeiras vazias são objetos que me chamam atenção desde sempre, é como se evocassem um sentimento de falta e perda, e aquele pensamento silencioso de: "Não deveria ter alguém ali?". Foi a partir desses pensamentos que saí a procura de rastros e vestígios que comprovem a presença de alguém naquele local, como uma almofada, as jaquetas nos encostos das cadeiras, os cobertores desdobrados do lado da cama... É a investigação de vestígios sobre o que tem de mais oculto e afetuoso em cada fotografia, que, muitas vezes inconscientemente, temos diversas sensações devido à provocação visual que cada fotografia nos dá, os objetos cotidianos possuem esse poder...

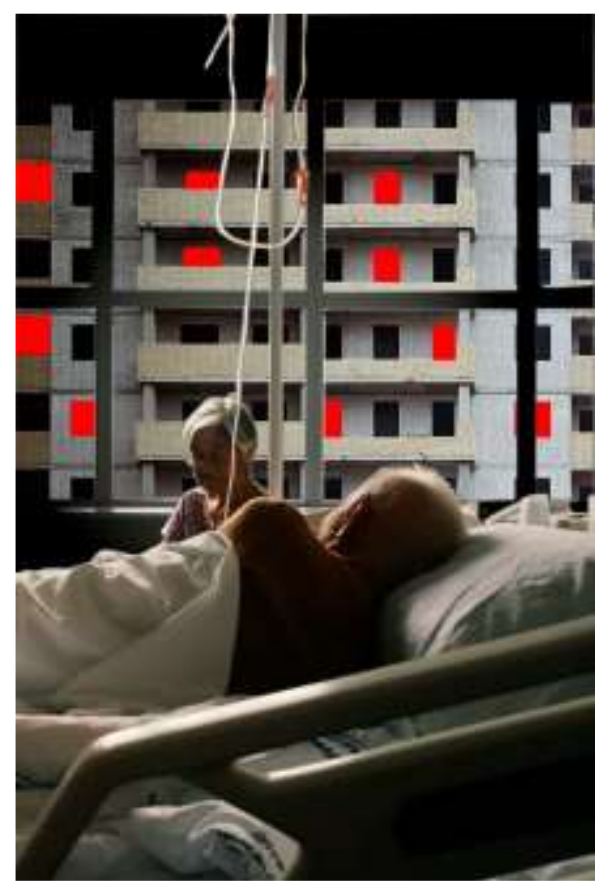

Imagem 4 - Em funcionamento, mas inacabadas... - Fonte: Registro pessoal, 2018 
$\mathrm{Na}$ foto acima, coloquei meus questionamentos em relação às mulheres de minha família. Na foto, estão minha avó e minha bisavó, na época com 100 anos. Muitas vezes presenciei uma conversa entre elas, mãe e filha já em uma idade avançada, conversando em japonês, as vezes até gritando porque uma não escutava a outra. A fotografia acima, é uma das que considero mais íntima, silenciosa e gritante ao mesmo tempo, nesse momento em específico, nenhuma das duas estavam conversando, apenas trocavam olhares e gestos de carinhos silenciosos, como cobrir os pés descobertos, fechar a cortina, pois o sol estava batendo em seu rosto atrapalhando o sono, trocar de lenços úmidos devido ao calor... Foi um momento de silêncio que me causou muito barulho interno e externo. Duas vidas que se cuidaram a vida inteira, que tiveram seus desejos e vontades cortados pelo fato de serem mulheres, mas nunca deixaram de dar forças uma a outra.

"Em funcionamento, mas inacabadas...", por que inacabadas? Porque, por mais que estejam nesta idade avançada, sendo pessoas 'vividas', que viveram muito, pode-se dizer que elas possuem a estrutura, os pilares de sustentação para se manterem de pé, mas e seu interior? Suas pinturas externas, suas vontades não saciadas? Seus direitos de expressarem mágoas e felicidades?

Ao pensar cada vez mais cada fotografia e ver as potências, memórias, deslocamentos e intensidades que elas trazem não hesitei em continuar a buscar esses acontecimentos, a ficar sempre à espreita por pequenos gestos. Cada vez mais, quero poder seguir em frente e levar para vida todos os caminhos que esses encontros me possibilitam, nem que eu precise voltar para trás para escolher outra trajetória. Ou, como diz Garlet (2014, p. 46):

[...] não há como garantir uma evolução, apenas encontros com o outro, que vão nos tornando diferentes de nós mesmos. Não há a criação de uma identidade que vai se reafirmando numa mesma direção, mas infinitas possibilidades de ser que vamos experimentando em nossas andarilhagens -que nos fazem ziguezaguear, ir em frente, retornar, pegar desvios, nos perder (não necessariamente nesta ordem) -sem a preocupação de ter escolhido o melhor caminho naquele momento, mas aproveitando os encontros que ele nos permite.

Ou seja, esta pesquisa poética não terá um fim, até porque não tem nem um ponto de chegada. Posso enfim pensar que cheguei, que ultrapassei a linha de chegada, mas, quando perceber, estarei já em outra corrida, em outros mapas. Em outros territórios que estarão lá para questionar as certezas e conhecimentos, abalar e gerar fendas que possibilitem passagens e preenchimentos através de memórias, acontecimentos e vários devires.

\section{Conclusão}

Desde o momento que optei por realizar uma pesquisa $\mathrm{em}$ arte, tinha em mente que passaria por algumas dificuldades quanto a conceitos, materializações e sensações. Mas o fator mais complicado em uma pesquisa que mexe com o sensível e a poética é, justamente, este mergulho em si que se deixa transbordar para não ficar somente naquele interior que acaba ficando vazio caso não se movimente em devir.

Tomar como substrato de produção poética o cotidiano, mais especificamente o cotidiano familiar que se encontra em um território afetivo rodeado por algumas linhas de forças que tentam endurecer as subjetividades e os afetos, foi também um desafio nesta pesquisa. Em alguns momentos precisava ter um olhar estrangeiro para com essa familiaridade, o que é complicado porque, por mais que seja estrangeiro, ainda fala de mim.

Porém, percebi ser preciso que alguém tivesse esse olhar de fora justamente para trazer uma visão diferenciada, um olhar que tenta ver na vida potências de variação, diferença e demonstração de afeto. Diversas foram as dobras feitas durante este percurso, ao trazer para 
fora uma subjetividade endurecida através da fotografia, pude dobrá-la através de recortes, narrativas, memórias e materialização. Assim, pude sair também de meu lugar de impotência, sim, me sentia impotente em frente aos silêncios, em frente aos vazios que, na verdade, podiam ser preenchidos ou simplesmente adentrados para compartilhar afetos ali mesmo.

Olhando para trás, vejo o quanto de afetos esse trabalho reverbera em mim. Esta pesquisa foi uma forma de prática de liberdade com a qual pude dar voz a silêncios, preencher e costurar fraturas e, até mesmo, abrir algumas. Isso porque, ao colocar em prática essa liberdade, permiti retornos e operações para comigo mesma, possibilitando um retorno para minha vida e um cuidado de si que engloba as relações familiares, amorosas e de amizades...

Não vejo este trabalho como finalizado, até porque, como vou saber se é o início ou o fim? Posso estar no meio de algo muito maior, que espera por mais acontecimentos e produções. Meu desejo agora é continuar com andarilhagens e caminhos já pronta para uma próxima viagem, para fazer-me outra e produzir uma próxima leva de fotografias, um outro percurso ou processo de ressignificação sensível de si e do mundo...

\section{Referências}

FIGUEIREDO, F. P. D. Arte de viver, modos de vida e estética da existência em Michel Foucault. Ítaca, Rio de Janeiro, v. 15, p. 290-299, dez./2010. Disponível em: https://revistas.ufrj.br/index.php/Itaca/article/view/262. Acesso em: janeiro de 2021.

FOUCAULT, Michel. A ética do cuidado de si como prática da liberdade. In: FOUCAULT, Michel. Ética, sexualidade e política. p. 264 287. Rio de Janeiro: Forense Universitária, 2004.

GARLET, Francieli Regina et al. Pesquisar andarilho: cintilâncias e transbordamentos de uma docência. 2014.

ISOTANI, Mina. A representação do feminino: a construção identitária da mulher japonesa moderna. 2016. Tese de Doutorado. Universidade de São Paulo.

KOSSOY, Boris. Fotografia \& História. 4. edição. São Paulo: Atelier Editorial, 2012.

LUERSEN, Paula Cristina. Torreão, lugar de rastros. 2018.

MANSANO, Sonia Regina Vargas. Sujeito, subjetividade e modos de subjetivação na contemporaneidade. Revista de Psicologia da UNESP, v. 8, n. 2, 2009.

VAZ, T.; MARTINS, R. Devir-febre-amarelo: entre a cidade e a fotografia entram perceptos e afectos. In: $15^{\circ}$ ENCONTRO INTERNACIONAL DE ARTE E TECNOLOGIA (\#15.ART), 2016, Brasília. Anais... Brasília: Universidade de Brasília, 2016. p. 438-444.

REY, Sandra. Por uma abordagem metodológica da pesquisa em artes visuais. In: BRITES, Blanca Luz; TESSLER, Élida Starosta. O meio como ponto zero: metodologia da pesquisa em artes plásticas. Porto Alegre: UFRGS, 1996. p. 123- 140.

ROLNIK, Suely. Uma insólita viagem à subjetividade fronteiras com a ética e a cultura. 1997. Disponível em: https://www.pucsp.br/nucleodesubjetividade. Acesso em: janeiro de 2021. 
ROLNIK, Suely; GUATTARI, Félix. Micropolítica: cartografias do desejo. Petrópolis, RJ: Vozes.

STUBS, Roberta. A/r/tografia de um corpo experiência: arte contemporânea, feminismos e produção de subjetividade. 2015.

\section{Sobre as autoras}

Fernanda Ayumi Sakuma. Graduada em Artes Visuais pela Universidade Estadual de Maringá. E-mail: fayumisakuma@gmail.com.

Roberta Stubs. Artista, pesquisadora e professora. Doutora em Psicologia, Arte e Gênero pela Universidade Estadual Paulista e docente de Artes Visuais da Universidade Estadual de Maringá. Coordenadora do DOBRA, grupo de pesquisa em arte, subjetividade, educação e diferença. E-mail: robertastubs@gmail.com. 